\title{
A retrospective observational study examining the characteristics and outcomes of tumours diagnosed within and without of the English NHS Bowel Cancer Screening Programme
}

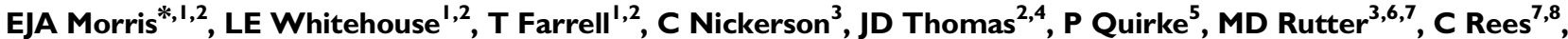 PJ Finan ${ }^{4,9}$, JR Wilkinson ${ }^{2,7}$ and J Patnick ${ }^{3}$}

'Colorectal Cancer Epidemiology Group, Leeds Institute of Molecular Medicine, University of Leeds, Level 6, Bexley Wing, St James's Institute of Oncology, St James's Hospital, Leeds LS9 7TF, UK: ${ }^{2}$ Northern and Yorkshire Cancer Registry and Information Service, Level 6, Bexley Wing, St James's Institute of Oncology, St James's Hospital, Leeds LS9 7TF, UK; ${ }^{3}$ NHS Cancer Screening Programmes, Fulwood House, Old Fulwood Road, Sheffield, UK; ${ }^{4}$ National Cancer Intelligence Network, I 8th Floor Portland House, Bressenden Place, London SWIE 5RS, UK; ${ }^{5}$ Pathology and Tumour Biology, Leeds Institute for Molecular Medicine, University of Leeds, St James's University Hospital, Level 4 Wellcome Brenner Building, Beckett Street Leeds LS9 7TF, UK; ' Tees Bowel Cancer Screening Centre, University Hospital of North Tees, Hardwick, Stockton-on-Tees, Cleveland TSI 9 8PE, UK; ${ }^{7}$ School of Medicine, Health and Pharmacy, University of Durham, Durham TS 17 6BH, UK; ${ }^{8}$ South Tyneside NHS Foundation Trust, The James Cook University Hospital, Marton Road, Middlesbrough TS3 3BW, UK; ${ }^{9}$ John Goligher Colorectal Unit, Leeds General Infirmary, Great George Street, Leeds LSI 3EX, UK

BACKGROUND: Colorectal cancer is common in England and, with long-term survival relatively poor, improving outcomes is a priority. A major initiative to reduce mortality from the disease has been the introduction of the National Health Service (NHS) Bowel Cancer Screening Programme (BCSP). Combining data from the BCSP with that in the National Cancer Data Repository (NCDR) allows all tumours diagnosed in England to be categorised according to their involvement with the BCSP. This study sought to quantify the characteristics of the tumours diagnosed within and outside the BCSP and investigate its impact on outcomes. METHODS: Linkage of the NCDR and BCSP data allowed all tumours diagnosed between July 2006 and December 2008 to be categorised into four groups; screen-detected tumours, screening-interval tumours, tumours diagnosed in non-participating invitees and tumours diagnosed in those never invited to participate. The characteristics, management and outcome of tumours in each category were compared.

RESULTS: In all, 76943 individuals were diagnosed with their first primary colorectal cancer during the study period. Of these 2213 (2.9\%) were screen-detected, $623(0.8 \%)$ were screening-interval cancers, 1760 (2.3\%) were diagnosed in individuals in nonparticipating invitees and 72437 (94.1\%) were diagnosed in individuals not invited to participate in the programme due to its ongoing roll-out over the time period studied. Screen-detected tumours were identified at earlier Dukes' stages, were more likely to be managed with curative intent and had significantly better outcomes than tumours in other categories.

CONCLUSION: Screen-detected cancers had a significantly better prognosis than other tumours and this would suggest that the BCSP should reduce mortality from colorectal cancer in England.

British Journal of Cancer (2012) I 07, 757-764. doi:I0.1038/bjc.20 I2.33I www.bjcancer.com

Published online 31 July 2012

(C) 2012 Cancer Research UK

Keywords: colorectal cancer; screening; survival

Colorectal cancer is the third most common cancer in the United Kingdom and the second leading cause of cancer death (Cancer Research UK, 2011). Long-term outcomes from the disease in the United Kingdom are poor with international survival comparisons showing that survival is significantly lower than in many comparable countries (Coleman et al, 2011; Morris et al, 2011). Redressing this survival deficit is a priority for the National Health Service (NHS) (Department of Health, 2007).

Numerous studies have now demonstrated that regular screening reduces the risk of dying from colorectal cancer (Mandel et al, 1993; Kronborg et al, 1996; Hardcastle et al, 1996; Jorgensen et al,

*Correspondence: Dr EJA Morris; E-mail: eva.morris@nycris.leedsth.nhs.uk Received 16 April 2012; revised 21 June 2012; accepted 26 June 2012; published online 31 July 2012
2002; Faivre et al, 2004) so, to improve colorectal cancer outcomes, the NHS implemented a national Bowel Cancer Screening Programme (BCSP). The scheme began in July 2006 and rolled out incrementally across the country achieving national coverage in 2010. Initially, it offered screening to all men and women resident in England and registered with a general practitioner between the ages of 60 and 69 years but from 2010 it began to be extended to include everyone up to the age of 74 years. Older people may also self-refer into the programme. The screening process has been described in detail elsewhere (Logan et al, 2011) but, in brief, eligible individuals are automatically sent an invitation to participate from their regional screening hub and, unless they indicate otherwise, sent a faecal occult blood test (FOBt) screening kit. The kit is completed by the participant and returned by post to the relevant hub. Those who test positive are then offered a colonoscopy or further investigations at their local 
screening centre to determine if cancer or adenomas are present. If so they are then referred to their local multi-disciplinary colorectal cancer team for appropriate treatment for the disease or, for adenomas, entered into a surveillance programme. Those who test negative are invited to be screened again after 2 years. Evidence from the first prevalent round of screening by the NHS BCSP has demonstrated an overall participation rate of $49.6 \%$ of men and $54.4 \%$ of women although involvement varied by both age and level of deprivation too (Logan et al, 2011; von Wagner et al, 2011).

The NHS BCSP actively audits its performance and has collected comprehensive data about all individuals eligible for the scheme in a single national system. The data gathered cover all aspects of the screening process as well as detailed pathological information about any adenomas and tumours detected. This system allows the characteristics and patterns of identification of screen-detected tumours to be quantified. To compare screen-detected tumours to those identified symptomatically, however, information is needed about all the other colorectal tumours identified in the country. Such information is available from the National Cancer Data Repository (NCDR; National Cancer Intelligence Network, 2011) (that has recently been developed by the National Cancer Intelligence Network (NCIN) and the United Kingdom Association of Cancer Registries (UKACR)) which contains information about the characteristics and management of all colorectal tumours diagnosed in England. Linking these two data sets enables screendetected tumours to be identified within a population-based data set of all other colorectal tumours. It also enables all tumours to be categorised into groups based on their involvement or otherwise in the screening programme. For example, it is possible to identify those that are screen-detected, those that occur in the interval between a negative screening test and the date the next test is due, those that occur in invited non-participants of the scheme and those that occur in individuals never invited to participate in the programme. The aim of this study was to exploit this linked data set to examine the characteristics of the tumours in each group and to investigate any variation between the tumours in each category and their subsequent management.

\section{MATERIALS AND METHODS}

All patients diagnosed with their first primary colorectal cancer (International Classification of Disease Version 10, World Health Organisation, 2004; (ICD10) codes C18-C20) diagnosed in England between 4 July 2006 and the 31 December 2008 were extracted from the NCDR. This time period was selected as the NHS BCSP began in July 2006 and, at the time of analysis, the NCDR was complete for cancer registrations up until the end of 2008. As such, this time period represented the maximum available cross-over between the two data sets.

Information taken from the cancer registry data within the NCDR included age, sex, site of tumour, Dukes' stage of disease at diagnosis (the only currently nationally available staging variable) and, where relevant, date of death. Management information for each tumour was also extracted from the Hospital Episode Statistics (HES) data within the resource. A primary procedure was sought for every individual who could be identified in both the registry and HES data sets. Initially, major resections (as defined by the OPCS Classification of Interventions and Procedures version 4 (NHS Connecting for Health, 2009a, b) (OPCS4) codes in Appendix 1) were identified for all linked patients within 12 months of the date of diagnosis of the tumour. If a patient underwent two or more major colorectal resections during different episodes of treatment, then the first operation was used. If a patient underwent two or more procedures during the same episode, then the most radical or extensive procedure was used. If no major resection could be identified for an individual, then their hospital episodes were searched again for other surgical interventions in the order of minor resection and then palliative procedures such as bypass, formation of a stoma or insertion of a stent (defined using the OPCS4 (NHS Connecting for Health, 2009a, b) codes in Appendix 1). If no primary procedure could be identified but an individual linked to HES, then individuals were allocated to the 'no surgical treatment in the NHS category'. No management information was available for some individuals as they could not be identified in HES (because, for instance, they were treated privately or died without receiving any treatment) and were included in a separate category.

This extract of NCDR data was then linked at a patient level to the NHS BCSP data set using all or combinations of the identifiers of NHS number, date of birth, postcode and sex. Tumours were then categorised into four groups (Table 1).

The first category of tumours was called 'screen-detected' and included all cancers that were identified as a result of investigations undertaken within the screening programme and that were identified as such in the BCSP data set. This group included both individuals invited to participate as they were within the eligible age range as well those who self-referred into the scheme. The next category was called 'interval' tumours. These were defined as all tumours diagnosed in the interval between the closure of a previous negative screening episode up to the date the next screening test was due or, if a person was screened at 69 years and so was no longer in the eligible age range for the scheme, up to 2 years after their last negative screening episode. The third category

Table I Tumour categories

\begin{tabular}{ll}
$\begin{array}{l}\text { Tumour } \\
\text { category }\end{array}$ & Tumour category definition \\
\hline I. Screen detected & All tumours diagnosed as a result of investigations undertaken within the screening programme \\
2. Interval & $\begin{array}{l}\text { All tumours diagnosed in the interval between the closure of a previous negative screening episode and the due date of the next appropriate } \\
\text { screening test }\end{array}$ \\
3. Non-participants & All tumours diagnosed in individuals who had refrained from any involvement in the screening programme
\end{tabular}

Under age All tumours identified in individuals who (at diagnosis) were too young to be eligible to participate in screening programme

4. Never invited All tumours diagnosed in individuals never invited to participate in the screening programme over the course of the study
Screening All tumours identified in individuals within the screening age range but who age range due to the gradual roll-out of the screening programme over the study period were not invited 
included all those tumours diagnosed in those invited to participate in the scheme but who declined. The final category was called 'never invited' and included all those diagnosed in individuals who were never invited to participate in the screening programme over the course of the study period. This group has been further broken down into different age groups according to potential eligibility for the scheme. These groups include those who (over the time period of this study) were not invited due to being too young (under the age of 60 years) or too old (over the age of 69 years) to be eligible for the scheme. The remainder were in the screening age range of 60-69 years but were not invited to participate over the course of this study due to the ongoing roll-out of the programme over the time period examined.

Comparisons were then made between tumours in each group in terms of sex, site of the tumour, Dukes' stage at diagnosis, treatment, 30-day post procedural mortality and 1-year survival. Tumours in the appendix, caecum, ascending colon, hepatic flexure and transverse colon (ICD10 C180-C184) were considered to be right-sided whereas those at the splenic flexure and in the descending colon, sigmoid colon and rectosigmoid junction were considered to be left-sided tumours (ICD10 C185-C19). Tumours overlapping two sites in the colon (C188) or with no site specified (C189) were included in a category called colon not otherwise specified. In all, 30-day post-primary procedure mortality was defined as the percentage of patients dead within 30 days of their primary procedure. The statistical significance of any differences in these characteristics across groups was assessed using the $\chi^{2}$ test. Survival time was calculated from the date of diagnosis to the date of death or when censored (31 December 2009). The statistical significance of differences in survival time was assessed using the log-rank test.

\section{RESULTS}

Over the study period 4596 tumours were diagnosed in individuals both eligible for and invited to participate in the screening programme. Of these $2123(48.2 \%)$ were screen-detected, 623 $(13.6 \%)$ were interval cancers and the remainder $1760(38.3 \%)$ occurred in individuals who were invited to participate but refused. Of the screen-detected tumours 53 (2.5\%) occurred in individuals who were outside the eligible age range of the scheme but had self referred into it. A further 72437 tumours were diagnosed in the population across all age ranges. Of these 15265 occurred in individuals in the screening age range but who had not been invited to participate due to the ongoing roll-out of the programme. Over the study period the total number of individuals diagnosed with a colorectal tumour was 76943 .

There were significant differences in the characteristics of the individuals and tumours between the groups (Table 2) and, due to the number of individuals included in the study, the majority of the differences between groups are statistically significant. For instance, the male/female distribution varied greatly between tumour categories and a significantly higher proportion of screen-detected tumours were diagnosed in males than in females $(69.2 \%$ vs $61.0 \%$ in the never-invited group of screening age range $P<0.001)$.

Table 2 Characteristics of the study population

\begin{tabular}{|c|c|c|c|c|c|c|c|c|c|c|c|c|c|c|}
\hline \multirow[b]{2}{*}{ Characteristic } & \multicolumn{2}{|c|}{$\begin{array}{l}\text { Screen } \\
\text { detected }\end{array}$} & \multicolumn{2}{|c|}{ Interval } & \multicolumn{2}{|c|}{$\begin{array}{c}\text { Non- } \\
\text { participant }\end{array}$} & \multicolumn{2}{|c|}{$\begin{array}{c}\text { Never } \\
\text { invited }(<60)\end{array}$} & \multicolumn{2}{|c|}{$\begin{array}{c}\text { Never } \\
\text { invited (60-69) }\end{array}$} & \multicolumn{2}{|c|}{$\begin{array}{c}\text { Never } \\
\text { invited }(>69)\end{array}$} & \multicolumn{2}{|c|}{ Total } \\
\hline & $n$ & $\%$ & $n$ & $\%$ & $n$ & $\%$ & $n$ & $\%$ & $n$ & $\%$ & $n$ & $\%$ & $n$ & $\%$ \\
\hline \multicolumn{15}{|l|}{ Sex } \\
\hline Male & 1470 & 69.2 & 350 & 56.2 & 1100 & 62.5 & 6821 & 55.9 & 9307 & 61.0 & 23184 & 51.6 & 42232 & 54.9 \\
\hline Female & 653 & 30.8 & 273 & 43.8 & 660 & 37.5 & 5387 & 44.1 & 5958 & 39.0 & 21780 & 48.4 & 34711 & 45.1 \\
\hline \multicolumn{15}{|l|}{ IMD income category } \\
\hline Most affluent & 457 & 21.5 & 116 & 18.6 & 267 & 15.2 & 2612 & 21.4 & 3305 & 21.7 & 8981 & 20.0 & 15738 & 20.5 \\
\hline 2 & 451 & 21.2 & 134 & 21.5 & 331 & 18.8 & 2460 & 20.2 & 3461 & 22.7 & 9741 & 21.7 & 16578 & 21.5 \\
\hline 3 & 473 & 22.3 & 147 & 23.6 & 339 & 19.3 & 2391 & 19.6 & 3149 & 20.6 & 9814 & 21.8 & 16313 & 21.2 \\
\hline 4 & 422 & 19.9 & 106 & 17.0 & 350 & 19.9 & 2323 & 19.0 & 2760 & 18.1 & 8758 & 19.5 & 14719 & 19.1 \\
\hline Most deprived & 292 & 13.8 & 103 & 16.5 & 420 & 23.9 & 2092 & 17.1 & 2313 & 15.2 & 6920 & 15.4 & 12140 & 15.8 \\
\hline Unknown & 28 & 1.3 & 17 & 2.7 & 53 & 3.0 & 330 & 2.7 & 277 & 1.8 & 750 & 1.7 & 1455 & 1.9 \\
\hline \multicolumn{15}{|l|}{ Tumour site } \\
\hline Right colon & 416 & 19.6 & 223 & 35.8 & 518 & 29.4 & 3021 & 24.7 & 4036 & 26.4 & 14722 & 32.7 & 22936 & 29.8 \\
\hline Left colon & 1047 & 49.3 & 196 & 31.5 & 562 & 31.9 & 4054 & 33.2 & 5304 & 34.7 & | 3989 & 31.1 & 25152 & 32.7 \\
\hline Colon NOS & 79 & 3.7 & 48 & 7.7 & 139 & 7.9 & 881 & 7.2 & 1119 & 7.3 & 4787 & 10.6 & 7053 & 9.2 \\
\hline Rectum & 581 & 27.4 & 156 & 25.0 & 541 & 30.7 & 4252 & 34.8 & 4806 & 31.5 & II 466 & 25.5 & 21802 & 28.3 \\
\hline \multicolumn{15}{|l|}{ Primary procedure } \\
\hline Major resection & 1698 & 80.0 & 472 & 75.8 & 1226 & 69.7 & 8492 & 69.6 & 10818 & 70.9 & 26039 & 57.9 & 48745 & 63.4 \\
\hline Minor resection & 198 & 9.3 & 20 & 3.2 & 60 & 3.4 & 375 & 3.1 & 483 & 3.2 & 1768 & 3.9 & 2904 & 3.8 \\
\hline Palliative procedure & 17 & 0.8 & 23 & 3.7 & 104 & 5.9 & 628 & 5.1 & 767 & 5.0 & 2494 & 5.5 & 4033 & 5.2 \\
\hline No in-patient NHS procedure & $1 \mid 4$ & 5.4 & 85 & 13.6 & 290 & 16.5 & 1950 & 16.0 & 2484 & 16.3 & | 1358 & 25.3 & $1628 \mid$ & 21.2 \\
\hline No information & 96 & 4.5 & 23 & 3.7 & 80 & 4.5 & 763 & 6.3 & 713 & 4.7 & 3305 & 7.4 & 4980 & 6.5 \\
\hline \multicolumn{15}{|l|}{ Duke's stage at diagnosis } \\
\hline A & 614 & 28.9 & 74 & 11.9 & 192 & 10.9 & 1237 & 10.1 & 1667 & 10.9 & 3990 & 8.9 & 7774 & 10.1 \\
\hline B & 517 & 24.4 & 137 & 22.0 & 385 & 21.9 & 2662 & 21.8 & 3889 & 25.5 & || 26 | & 25.0 & $1885 \mid$ & 24.5 \\
\hline C & 497 & 23.4 & 196 & 31.5 & 514 & 29.2 & 3499 & 28.7 & 4187 & 27.4 & 9851 & 21.9 & 18744 & 24.4 \\
\hline $\mathrm{D}$ & 121 & 5.7 & 130 & 20.9 & 315 & 17.9 & 2304 & 18.9 & 2621 & 17.2 & 6858 & 15.3 & 12349 & 16.0 \\
\hline Unknown & 374 & 17.6 & 86 & 13.8 & 354 & 20.1 & 2506 & 20.5 & 2901 & 19.0 & 13004 & 28.9 & 19225 & 25.0 \\
\hline Total & 2123 & & 623 & & 1760 & & 12208 & & 15265 & & 44964 & & 76943 & \\
\hline
\end{tabular}

Abbreviations: IMD = Index of Multiple Deprivation; NHS = National Health Service; NOS = Not Otherwise Specified. 


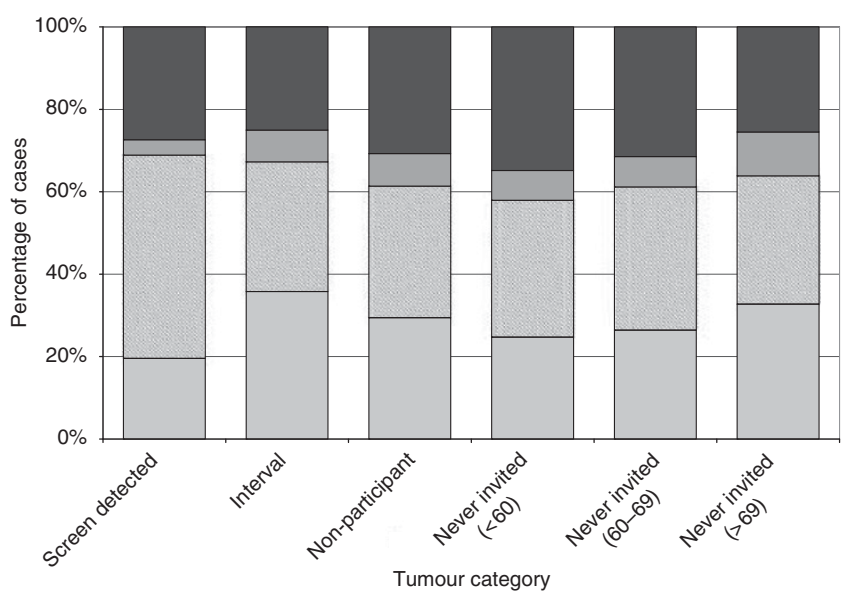

Figure I Distribution of tumours by their location in the bowel across the tumour categories.

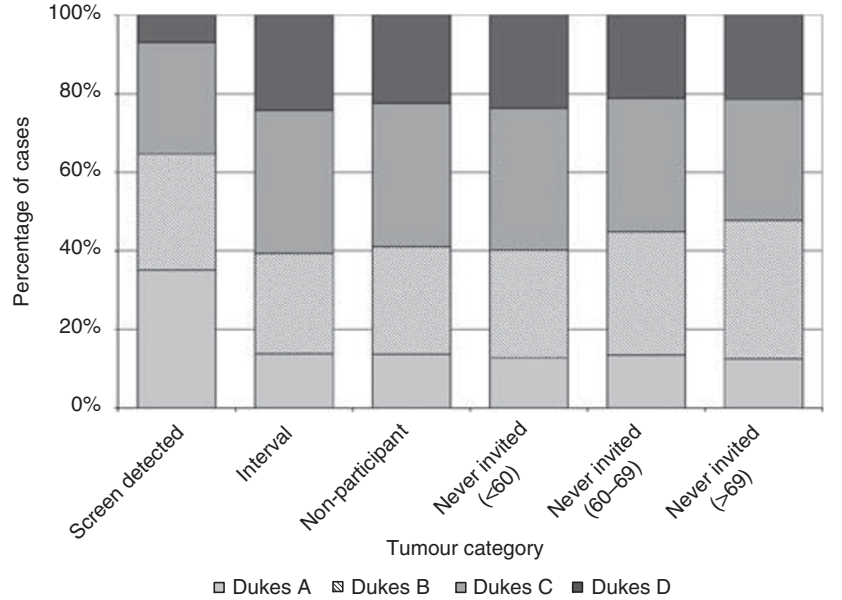

Figure 2 Distribution of tumours by stage at diagnosis across the tumour categories (staged cases only).

There were also differences in the proportion of individuals in each category in terms of the level of socio-economic deprivation of their area of residence. A significantly higher proportion of tumours among non-participants $(23.9 \%)$ were diagnosed in individuals who resided in the most deprived areas of the country while across the other tumour categories the proportion in this group was relatively constant ranging between $13.8 \%$ and $17.1 \%$ $(P<0.001$ across all groups).

There were also differences between the locations of tumours within the bowel between the groups (Figure 1). A greater proportion of screen-detected tumours compared with those arising in the never-invited group of identical age to the screening programme $(77.1 \%$ vs $66.2 \% P<0.01)$ were located within the left side of the colon or the rectum compared with the right side of the bowel (figures ranged between $53.7 \%$ and $68.0 \%$ in the other tumour categories).

Tumours diagnosed within the screening programme were also significantly more likely to be of an earlier stage than those diagnosed in the never-invited group of screening age (Figure 2, $P<0.01)$. After excluding tumours for which no staging information was available $35.1 \%$ of screen-detected tumours were Dukes' A at diagnosis compared with between $12.5 \%$ and $13.8 \%$ across the other tumour categories. Likewise only $6.9 \%$ of screen-detected tumours had metastatic disease at diagnosis (or Dukes' D disease) compared with between $21.2 \%$ and $24.2 \%$ in the other categories.

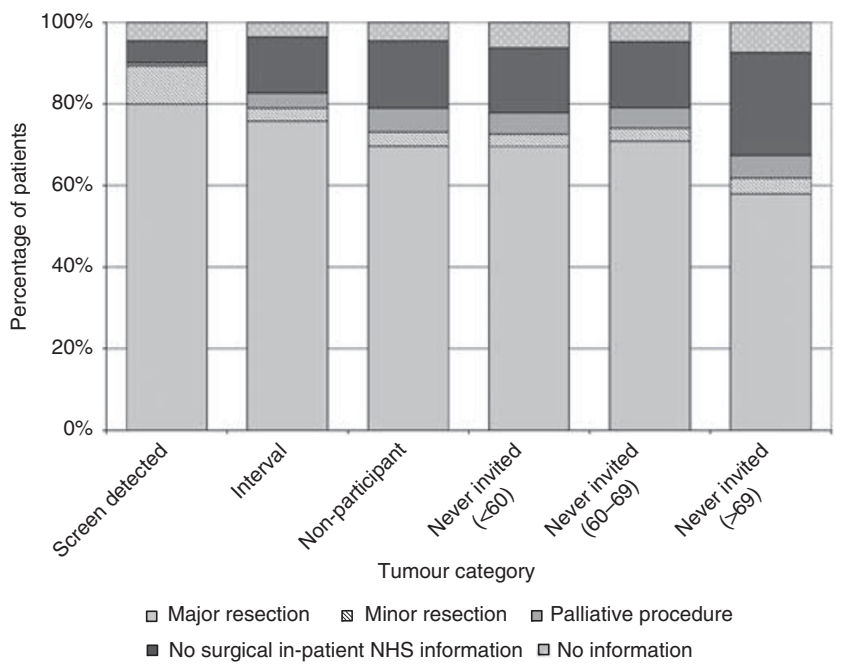

Figure 3 The distribution of primary procedures used to treat the tumours in each category.

There were also major differences in the treatments used to manage tumours in each of the categories (Figure 3). A significantly greater proportion of screen-detected tumours received both major resections $(80.0 \%)$ and minor resections (where comparable figures were $70.9 \%$ and $3.2 \%$, respectively, $P<0.01$ ). The proportion of cases for which no NHS surgical procedure could be identified was also significantly smaller for screendetected cancers at $5.4 \%$. In other categories, the proportion ranged from $13.6 \%$ to $26.3 \%$. Among those who underwent some form of surgical procedure there was also a significant difference across groups in the 30 -day post procedure mortality (Table 3). There was a $1.1 \% 30$-day mortality rate among individuals who had a major resection for screen-detected tumours compared with a rate of $2.8 \%$ in the comparable age range neverinvited group $(P<0.01)$. There was no significant difference in the 30 -day post operative mortality rate for major resections between individuals with tumours in the interval category compared with those in the never-invited screening age range category $(2.3 \%$ vs $2.8 \%, P=0.273)$.

Figure 4 and Table 4 demonstrate that there were also longer term survival differences between each of the tumour categories and, again, screen-detected tumours had the best prognosis. One-year survival in the screen-detected category was $95.9 \%$ (95\% confidence interval (CI) 94.9-96.6\%) compared with $79.6 \%$ (95\% CI $79.0-80.3 \%)$ in the never-invited group of screen age $(P<0.01)$. Across the other groups the same figures ranged from $63.5 \%$ (95\% CI $63.0-63.9 \%)$ to $83.9 \%$ (95\% CI $83.3-84.6 \%)$ $(P<0.001)$. It is also of note that patients with tumours in the interval category had 1-year survival comparable to that of those in the never-invited screening age range category $(78.4 \%(95 \% \mathrm{CI}$ $75.0-81.5 \%$ ) vs $79.6 \%$ (95\% CI 79.0-80.3\%), respectively, $P=0.548$ ).

\section{DISCUSSION}

This study has enabled tumours identified by the NHS BCSP to be identified within a population-based data set of all other colorectal tumours diagnosed in England. It has also enabled the characteristics of tumours to be compared across groups depending on the extent of involvement with the BCSP. This has shown that screendetected tumours have different characteristics to those detected symptomatically being found more commonly in males than in females and are more likely to be found in the left side of the bowel. The study has also shown they have a significantly better prognosis than non-screen-detected tumours presenting at an 
Table 3 Thirty-day post procedure mortality following surgical treatments used to manage tumours in each of the tumour categories

\begin{tabular}{|c|c|c|c|c|c|c|c|c|c|}
\hline \multirow[b]{3}{*}{ Tumour category } & \multicolumn{3}{|c|}{ Major resection } & \multicolumn{3}{|c|}{ Minor resections } & \multicolumn{3}{|c|}{ Palliative procedures } \\
\hline & \multirow[b]{2}{*}{ Total procedures } & \multicolumn{2}{|c|}{$\begin{array}{l}\text { Deaths within } \\
30 \text { days }\end{array}$} & \multirow[b]{2}{*}{ Total procedures } & \multicolumn{2}{|c|}{$\begin{array}{l}\text { Deaths within } \\
30 \text { days }\end{array}$} & \multirow[b]{2}{*}{ Total procedures } & \multicolumn{2}{|c|}{$\begin{array}{c}\text { Deaths within } \\
30 \text { days }\end{array}$} \\
\hline & & $n$ & $\%$ & & $n$ & $\%$ & & $n$ & $\%$ \\
\hline Screen detected & 1698 & 18 & I.I & 198 & 0 & 0.0 & 17 & 0 & 0.0 \\
\hline Interval & 472 & II & 2.3 & 20 & 0 & 0.0 & 23 & 3 & 13.0 \\
\hline Non-participant & 1226 & 46 & 3.8 & 60 & 0 & 0.0 & 104 & 14 & 13.5 \\
\hline Never invited $(<60)$ & 8492 & 128 & 1.5 & 375 & 5 & 1.3 & 628 & 69 & 11.0 \\
\hline Never invited (60-69) & 10818 & 307 & 2.8 & 483 & 13 & 2.7 & 767 & 119 & 15.5 \\
\hline Never invited $(>69)$ & 26039 & 2090 & 8.0 & 1768 & 48 & 2.7 & 2494 & 503 & 20.2 \\
\hline Total & 48745 & 2600 & 5.3 & 2904 & 66 & 2.3 & 4033 & 708 & 17.6 \\
\hline
\end{tabular}

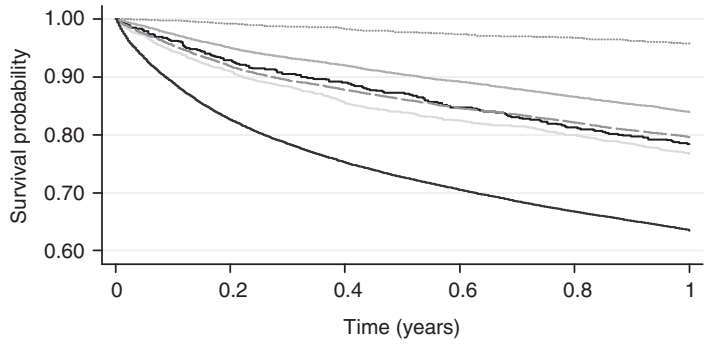

\begin{tabular}{|c|c|c|c|c|c|c|}
\hline \multirow[b]{2}{*}{$\begin{array}{l}\text { Number at risk } \\
\text { Screen detected }\end{array}$} & \\
\hline & 2122 & 2106 & 2087 & 2067 & 2054 & \\
\hline Interval & 621 & 577 & 553 & 526 & 505 & \\
\hline Non-participant & 1726 & 1571 & 1475 & 1423 & 1380 & \\
\hline Never invited $(<60)$ & 12111 & 11508 & 11146 & 10804 & 10485 & \\
\hline Never invited (60-69) & 15081 & 13852 & 13238 & 12757 & 12388 & \\
\hline ever invited (>69) & 42891 & 35433 & 32263 & 30250 & 28625 & \\
\hline & --- & $\begin{array}{l}\text { Screen det } \\
\text { Non-partici } \\
\text { Never invite }\end{array}$ & $\begin{array}{l}\text { ed } \\
\text { t } \\
60-69)\end{array}$ & $=1$ & $\begin{array}{l}\text { val } \\
\text { er invited }(< \\
\text { er invited }(<\end{array}$ & \\
\hline
\end{tabular}

Figure 4 One-year survival by tumour category.

Table 4 Crude I-year survival

\begin{tabular}{lcc}
\hline Tumour category & $\begin{array}{c}\text { Percentage } \\
\text { I-year survival }\end{array}$ & $\begin{array}{c}\text { 95\% Confidence } \\
\text { intervals }\end{array}$ \\
\hline Screen detected & 95.9 & $94.9-96.6$ \\
Interval & 78.4 & $75.0-81.5$ \\
Non-participant & 76.8 & $76.8-74.7$ \\
Never invited $(<60)$ & 83.9 & $83.3-84.6$ \\
Never invited (60-69) & 79.6 & $79.0-80.3$ \\
Never invited $(>69)$ & 63.5 & $63.0-63.9$ \\
\hline
\end{tabular}

earlier stage of disease and being more likely to be managed electively and with curative intent. They are also associated with both a lower 30-day post procedural mortality and improved 1 -year survival.

These findings are all consistent with other studies. Several other studies have shown that a higher proportion of screen-detected tumours are identified in males as opposed to females. This is a particularly striking and counterintuitive finding as evidence indicates that females are significantly more likely to participate in screening than males (Logan et al, 2011; von Wagner et al, 2011). While the incidence and prevalence of colorectal cancer is higher in males than in females, which may partly explain this phenomenon (Regula et al, 2006; Brenner et al, 2007) the proportion of males in the screen-detected group was significantly greater than in both the interval cancer and never-invited screening age range group and this would suggest there are fewer women in the screen-detected group than would be anticipated based on sex-specific incidence patterns alone. Other studies have observed similar trends with, for example, a higher proportion of screen-detected cancers being identified in men as opposed to women in the Scottish BCSP(Steele et al, 2011). There is growing evidence to indicate this phenomenon is explained by the fact that there are major sex differences in the performance of FOBt as the tests have a much higher sensitivity in males rather than in females (UK Colorectal Cancer Screening Pilot Group, 2004; Malila et al, 2008; Brenner et al, 2010). This evidence in combination with the knowledge that there are other gender differences in presentation of colorectal cancer relating to age (Brenner et al, 2007) and tumour site (Steele et al, 2011) should inform future efforts to maximise the efficacy of BCSPs.

Increasing deprivation has been shown to be negatively associated with participation in the bowel cancer screening (Weller et al, 2007; von Wagner et al, 2009; Moss et al, 2011). This may partly explain the observation that a much higher proportion of tumours among non-participants of the BCSP occurred in those residing in the most deprived areas of the country. Interventions to increase participation rates in socioeconomically deprived areas are, therefore, important.

Differences in the site of tumours within the bowel were observed across the different tumour categories in the study with screen-detected tumours having a significant higher proportion of left-sided tumours. This trend has also been seen in other studies (Steele et $a l, 2011$ ) and may be explained by FOBt being less effective at detecting right-sided tumours due to digestive transit. The test works by identifying haemoglobin released from bleeding tumours. Blood released from tumours in the right of the colon has to travel along a greater length of the bowel than that from tumours in the left of the colon and this may lead to a greater chance of the haemoglobin being degraded as it passes through the bowel. Degraded haemoglobin will not react with the FOBt and so, potentially, lead to more false negative results for right-sided tumours. Again, this information should help inform future design of the BCSPs.

This study also demonstrated that a larger proportion of screendetected tumours are identified at an early stage than those detected symptomatically. This trend has also been seen in many other screening studies and programmes and is part of the mechanism by which screening improves outcomes for the disease (Mandel et al, 1993; Kronborg et al, 1996; Hardcastle et al, 1996; Lindhom et al, 2008; Steele et al, 2009; Paimela et al, 2010; Steele et al, 2011). Other studies have also observed, however, a lower proportion of Dukes A tumours in prevalent screening cycles than incident screening cycles (Steele et al, 2010a, b; Moss et al, 2011). This study is based on the initial roll-out of the NHS BCSP and, for the majority involved, these data will relate to their initial 'prevalent' screening cycle. In future, therefore, it is possible the stage profile of screen-detected tumours may improve still further. Unfortunately, this study is limited in determining the full impact 
of stage by the screening programme as it was not possible to ascertain the stage of every tumour in the cohort and, although the trend for the screening programme to identify tumours at an early stage was strong, it has not been conclusively proven due to relatively large amounts of missing staging data. The lack of these data are due to the fact that the study is based on the routine cancer registry data available in the NCDR and, previously, these organisation have struggled to capture this data item for all cases of cancer. Significant efforts are being made by registries, however, to increase the ascertainment of staging data and in future it is anticipated this variable will be much better populated so allowing for the trends observed in this study to be confirmed.

These analyses have also demonstrated very different surgical management patterns across the different tumour groups. Almost $90 \%$ of individuals with screen-detected tumours received a resection for their disease, which is much higher than any other group. This will be linked to the fact that those who participate in screening appear to be healthier than those who do not (von Wagner et al, 2009). Screen-detected tumours are also being identified at an early stage and, hence, are much more likely to be amenable to radical treatment. Finally, the 30 -day post procedural mortality associated with these treatments was significantly lower than in other tumour categories, which is a positive finding given the relatively high post-operative mortality rates seen in England (Morris et al, 2011). Other studies have observed similar effects (Goodyear et al, 2008; Scholefield et al, 2011; Suttie et al, 2011) and while this may well be due to patients who participate in the programme being of better health than their non-participating counterparts it could also relate to the earlier stage tumours detected in greater proportion by the BCSP carrying less risk than the later stage tumours diagnosed outside the programme.

Finally, this study also provides evidence from a populationbased setting to suggest that the outcomes from colorectal cancer can be improved by the introduction of a screening programme. Unfortunately, the data available only allow variation in survival to be quantified and this outcome measure may be problematic due to 'lead time bias' (i.e., the screening programme simply identifies tumours earlier so individuals appear to survive longer simply because they have been diagnosed earlier). To definitively prove a benefit to the BCSP trends in mortality would need to be assessed instead of survival as was done in the relevant randomised trials that originally investigated the effectiveness of such screening programmes (Hardcastle et al, 1996; Hewitson et al, 2008; Scholefield et al, 2011). Unfortunately though, the mortality data that would be required to undertake such analyses are not currently available and so this study has been restricted to survival analyses. In addition, due to the limited follow-up information available for the cohort only 1-year survival has been assessed. Efforts are being made, however, to acquire the mortality data that would be required to assess in full the impact of the BCSP.

In addition, due to the limited follow-up information available only 1-year survival has been assessed but as the programme continues the impact on long-term survival will be quantifiable by these data sets. Again, differences in case mix between the groups cannot be entirely dismissed as potentially accounting for the survival differences observed but the effects are large and it would seem unlikely that could explain in full the variation seen.

Another benefit to the linkage of the NCDR and NHS BCSP data sets is that it enables the number and characteristics of interval tumours to be quantified. This is important as, although some tumours may legitimately develop in their entirety over the course of a screening interval, the majority are likely to have already existed at screening but were simply not detected by the screening test. As such, the interval cancer rate in a screening population could be used as a performance indicator of the programme. It is encouraging to note, therefore, that the frequency of occurrence of interval cancers compares favourably with other screening trials and programmes. In addition, the management and prognosis of these tumours was not significantly different to those detected in individuals within the screening age range that had not been invited to participate over the time period of this study. This indicates that the BCSP is performing as would anticipated based on evidence from randomised trials (Hardcastle et al, 1996). More mature data with longer follow-up time and, hence, a greater number of complete screening intervals will be required from the NHS BCSP, however, before the interval cancer rate can be fully quantified.

During the time period the data in this study relate to the NHS BCSP as it was being rolled out across the country. The NHS BCSP did not attain national coverage until 2010 and, as such, the figures reported in this study represent preliminary findings of the scheme relating, in the main, to the initial or 'prevalent' screening cycle only. As the BCSP becomes more established a much larger population of individuals will have the opportunity to participate in it. In future, therefore, there will be sufficient numbers to divide the tumours groups into further subcategories to provide more informative analyses. For example, the screen-detected category could be subdivided depending on whether the tumour was diagnosed from an initial FOBt or as part of resulting surveillance due to the identification of adenomas. Likewise, the interval tumour category could be further subdivided into three subcategories: those who were identified with a cancer following the return of a negative FOBt kit, those who were diagnosed with a cancer following a positive FOBt kit but negative colonoscopy and those who had a cancer diagnosed following a negative surveillance test. The final category of non-participants could also be further subdivided into three groups: those who do not participate at all, those who begin the screening process but drop out before a conclusive outcome is determined and those who participate in a full cycle of screening but chose not to participate in any subsequent screening rounds. Very small numbers of individuals fall into these subgroups currently and this has prevented meaningful comparative analyses. As the NHS BCSP becomes more established, however, the numbers will grow so enabling robust analyses of the different subgroups. Patient level linkage of the NHS BCSP data set with the planned new national cancer registration system will ensure such data become routinely available in a more timely manner. Such information has the potential to optimise NHS bowel cancer screening services.

\section{ACKNOWLEDGEMENTS}

This paper is a contribution from the National Cancer Intelligence Network (www.ncin.org.uk) and the English registries (www.ukacr. org.uk). It is based on the information collected and quality assured by the regional cancer registries in England, specifically the Eastern Cancer Registration and Information Centre (Jem Rashbass), the Northern and Yorkshire Cancer Registry and Information Service (John Wilkinson and Brian Ferguson), the North West Cancer Intelligence Service (Tony Moran), the Oxford Cancer Intelligence Unit (Monica Roche), the South West Cancer Intelligence Service (Julia Verne), the Thames Cancer Registry (Elizabeth Davies), the Trent Cancer Registry (David Meechan) and the West Midlands Cancer Intelligence Unit (Gill Lawrence). While undertaking this work Eva Morris was funded by the Cancer Research UK Bobby Moore Fund (C23434/A9805) and Phil Quirke by Yorkshire Cancer Research (L354PA).

\section{Conflict of interest}

Julietta Patnick is the Director of the NHS Bowel Cancer Screening Programme. Claire Nickerson, Matt Rutter, Colin Rees and Phil Quirke are all employed (either full time or on a sessional basis) by the NHS Bowel Cancer Screening Programme. Tom Farrell was employed on a University of Leeds Research Grant provided by the NHS Bowel Cancer Screening Programme. 


\section{Author contributions}

EJAM, LEW, JDT, TF, CN, JW and JP were instrumental in accessing and managing the data upon which this study is based. LEW, JDT, TF, CN, PJF, PQ, MDR and CR produced clinically sound algorithms to extract data from the NCDR and BCSP for this study and EJAM was responsible for its statistical analysis. Clinical interpretation of the results was undertaken by PQ, PJF, MR and CR. All authors were involved in drafting and revising the paper and all authors approved the final version.

\section{REFERENCES}

Brenner H, Haug U, Hundt S (2010) Sex differences in performance of fecal occult blood testing. Am J Gastroenterol 105: 2457-2464

Brenner H, Hoffmeister M, Arndt V, Haug U (2007) Gender difference in colorectal cancer: implications for age at initiation of screening. $\mathrm{Br} J$ Cancer 96: 828-831

Cancer Research UK. CancerStats. http://info.cancerresearchuk.org/cancerstats/ types/bowel/?script=true (2011)

Coleman MP, Forman D, Bryant H, Butler J, Rachet B, Maringe C, Nur U, Tracey E, Coory M, Hatcher J, McGahan CE, Turner D, Marrett L, Gjerstorff ML, Johannesen TB, Adolfsson J, Lambe M, Lawrence G, Meechan D, Morris E, Middleton R, Steward J, Richards MA, ICBP Module 1 Working Group (2011) Cancer survival in Australia, Canada, Denmark, Norway, Sweden and the UK, 1995-2007 (the International Cancer Benchmarking Partnership): an analysis of population-based cancer registry data. Lancet 377(9760): 127-138

Department of Health Cancer Reform Strategy (2007) HMSO: London

Faivre J, Dancourt V, Lejeune C, Tazi MA, Lamour J, Gerard D, Dassonville F, Bonithon-Kopp C (2004) Reduction in colorectal cancer mortality by fecal occult blood screening in a French controlled study. Gastroenterology 126: 1674-1680

Goodyear SJ, Leung E, Menon A, Pedamallu S, Williams N, Wong LS (2008) The effects of population-based faecal occult blood test screening upon emergency colorectal cancer admissions in Coventry and north Warwickshire. Gut 57: 218-222

Hardcastle JD, Chamberlain JO, Robinson MHE, Moss SM, Amar SS, Balfour TW, James PD, Mangham CM (1996) Randomised controlled trial of faecal occult blood screening for colorectal cancer. Lancet 348: $1472-1477$

Hewitson P, Glasziou P, Watson E, Towler B, Irwig L (2008) Cochrane systematic review of colorectal cancer screening using the fecal occult blood test (hemoccult): an update. Am J Gastroenterol 103: 1541-1549

Jorgensen OD, Kronborg O, Fenger C (2002) A randomised study of screening for colorectal cancer using faecal occult blood testing: results after 13 years and seven biennial screening rounds. Gut 50: 29-32

Kronborg O, Fenger C, Olsen J, Jorgensen OD, Sondergaard O (1996) Randomised study of screening for colorectal cancer with faecal-occultblood test. Lancet 348: 1467-1471

Lindhom E, Brevinge H, Haglind E (2008) Survival benefit in a randomized clinical trial of faecal occult blood screening for colorectal cancer. $\mathrm{Br} J$ Surg 95: 1029-1036

Logan RFA, Patnick J, Nickerson C, Coleman L, Rutter MD, von Wagner C, on behalf of the English Bowel Cancer Screening Evaluation Committee (2011) Outcomes of the Bowel Cancer Screening Programme (BCSP) in England after the first one million tests. Gut. Epub ahead of print (10.1136/gutjnl-2011-300843)

Malila N, Oivanen T, Malminiemi O, Hakama M (2008) Test, episode and programme sensitivities of screening for colorectal cancer as a public health policy in Finalnd: experiemnetal design. Br Med J 337: a2261

Mandel J, Bond JH, Church TR, Snover DC, Bradley M, Schuman LM, Ederer F, for the Minnesota Colon Cancer Control Study (1993) Reducing mortality from colorectal cancer by screening for fecal occult blood. $N$ Engl J Med 328(19): 1365-1371

Morris EJ, Sandin F, Lambert PC, Bray F, Klint A, Linklater K, Robinson D, Pahlman L, Holmberg L, Moller H (2011) A population-based comparison of the survival of patients with colorectal cancer in England, Norway and Sweden between 1996 and 2004. Gut 60(8): 1087-1093

Morris EJA, Taylor EF, Thomas JD, Quirke P, Finan PJ, Coleman MP, Rachet B, Forman D. (2011) Thirty-day postoperative mortality after colorectal cancer surgery in England. Gut 60: 806-813

Moss SM, Campbell C, Melia J, Coleman D, Smith S, Parker R, Ramsell P, Patnick J, Weller DP (2011) Performance measures in three rounds of the English bowel cancer screening pilot. Gut 61(1): 101-107
National Cancer Intelligence Networkhttp://www.ncin.org.uk/collecting and_using_data/national_cancer_data_repository/default.aspx (2011)

NHS Connecting for Health OPCS Classification of Interventions and Procedures Version 4.5. Volume II - Alphabetical index. The Stationery Office: London (2009a)

NHS Connecting for Health OPCS Classification of Interventions and Procedures Version 4.5. Volume I - Tabular index. The Stationery Office: London (2009b)

Paimela H, Malila N, Palva T, Hakulinen T, Vertio H, Jarvinen H (2010) Early detection of colorectal cancer with faecal occult blood test screening. Br J Surg 97: 1567-1571

Regula J, Rupinski M, Kraszewska E, Polkowski M, Pachlewski J, Orlowska J, Nowacki MP, Butruk E (2006) Colonoscopy in colorectal cancer screening for detection of advanced neoplasia. N Engl J Med 355: 1863-1872

Scholefield JH, Robinson MHE, Mangham CM, Hardcastle JD (2011) Screening for colorectal cancer reduces emergency admissions. Eur J Surg Oncol 24: 47-50

Steele RJC, Kostourou I, McClements P, Watling C, Libby G, Weller D, Brewster DH, Black R, Carey FA, Fraser C (2010a) Effect of gender. age and deprivation on key performance indicators in a FOBT-based colorectal screening programme. J Med Screen 17(2): 68-74

Steele RJC, Kostourou I, McClements P, Watling C, Libby G, Weller D, Brewster DH, Black R, Carey FA, Fraser C (2010b) Effect of repeated invitation on uptake of colorectal cancer screening using faecal occult blood testing: analysis of prevalence and incidence screening. $\mathrm{Br} \mathrm{Med} \mathrm{J}$ 341: c5531

Steele RJC, McClements P, Watling C, Libby G, Weller D, Brewster DH, Black R, Carey FA, Fraser CG (2011) Interval cancers in a FOBT-based colorectal cancer population screening programme: implications for stage, gender and tumour site. Gut 61(4): 576-581

Steele RJC, McClements PL, Libby G, Black R, Morton C, Birrell J, Mowat NAG, Wilson JA, Kenicer M, Carey FA, Fraser CG (2009) Results from the first three rounds of the Scottish demonstration pilot of FOBT screening for colorectal cancer. Gut 58: 530-535

Suttie S, Shaikh I, Amin I, Daniel T, Yalamarthi S (2011) The effects of a screening programme on the outcomes of colorectal cancer. Colorectal Dis (in press)

UK Colorectal, Cancer Screening Pilot Group (2004) Results of the first round of a demonstration pilot of screening for colorectal cancer in the United Kingdom. Br Med J 329: 133-135

von Wagner C, Baio G, Raine R, Snowball J, Morris S, Atkin WS, Obichere A, Handley G, Logan RFA, Rainbow S, Smith S, Halloran S, Wardle J (2011) Inequalities in participation in an organized national colorectal cancer screening programme: results from the first 2.6 million invitations in England. Int J Epidemiol 40: 712-718

von Wagner C, Good A, Wright D, Rachet B, Obichere A, Bloom S, Wardle J (2009) Inequalities in colorectal cancer screening participation in the first round of the national screening programme in England. $\mathrm{Br} \mathrm{J}$ Cancer 101: S60-S63

Weller D, Coleman D, Robertson R, Butler P, Melia J, Campbell C, Parker R, Patnick J, Moss SM (2007) The UK colorectal cancer screening pilot: results of the second round of screening in England. $\mathrm{Br} J$ Cancer 97: 1601-1605

World Health Organisation (2004) ICD10 International Statistical Classification of Disease and Related Health Problems. World Health Organisation: Geneva

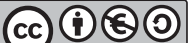

This work is licensed under the Creative Commons Attribution-NonCommercial-Share Alike 3.0 Unported License. To view a copy of this license, visit http:// creativecommons.org/licenses/by-nc-sa/3.0/ 


\section{APPENDIX 1}

Table A1: OPCS4 codes used to define primary procedures

\begin{tabular}{lll}
$\begin{array}{l}\text { Procedure } \\
\text { type }\end{array}$ & $\begin{array}{l}\text { OP-CS4 } \\
\text { code }\end{array}$ & OPCS4 code description \\
\hline $\begin{array}{l}\text { Major } \\
\text { resection }\end{array}$ & H01 & Emergency excision of appendix \\
& H02 & $\begin{array}{l}\text { Other excision of appendix } \\
\text { Total excision of colon and rectum }\end{array}$ \\
H04 & Total excision of colon \\
H05 & Extended excision of right hemicolon \\
H06 & Other excision of right hemicolon \\
H08 & Excision of transverse colon \\
H09 & Excision of left hemicolon \\
H10 & Excision of sigmoid colon \\
H11 & Other excision of colon \\
H12 & Extirpation of lesion of colon \\
H29 & Subtotal excision of colon \\
H33 & Excision of rectum \\
H341 & Open excision of lesion of rectum \\
X14 & Pelvic exenteration
\end{tabular}

Minor H201 Fibreoptic endoscopic snare resection of lesion of excision

H202 Fibreoptic endoscopic cauterisation of lesion of colon

H205 Fibreoptic endoscopic submucosal resection of lesion of colon

H206 Fibreoptic endoscopic resection of lesion of colon not elsewhere classified

H208 Endoscopic extirpation of lesion of colon other specified

H209 Endoscopic extirpation of lesion of colon unspecified

H231 Endoscopic snare resection of lesion of lower bowel using fibreoptic sigmoidoscope

H232 Endoscopic cauterisation of lesion of lower bowel using fibreoptic sigmoidoscope

H235 Endoscopic submucosal resection of lesion of lower bowel using fibreoptic sigmoidoscope

H236 Endoscopic resection of lesion of lower bowel using fibreoptic sigmoidoscope

H238 Endoscopic extirpation of lesion of lower bowel using fibreoptic sigmoidoscope other specified

H239 Endoscopic extirpation of lesion of lower bowel using fibreoptic sigmoidoscope unspecified
(Continued)

\begin{tabular}{|c|c|c|}
\hline $\begin{array}{l}\text { Procedure } \\
\text { type }\end{array}$ & $\begin{array}{l}\text { OP-CS4 } \\
\text { code }\end{array}$ & OPCS4 code description \\
\hline & H261 & $\begin{array}{l}\text { Endoscopic snare resection of lesion of sigmoid } \\
\text { colon using rigid sigmoidoscope }\end{array}$ \\
\hline & $\mathrm{H} 262$ & $\begin{array}{l}\text { Endoscopic cauterisation of lesion of sigmoid colon } \\
\text { using rigid sigmoidoscope }\end{array}$ \\
\hline & H266 & $\begin{array}{l}\text { Endoscopic submucosal resection of lesion of } \\
\text { sigmoid colon using rigid sigmoidoscope }\end{array}$ \\
\hline & $\mathrm{H} 267$ & $\begin{array}{l}\text { Endoscopic resection of lesion of sigmoid colon } \\
\text { using rigid sigmoidoscope not elsewhere classified }\end{array}$ \\
\hline & $\mathrm{H} 268$ & $\begin{array}{l}\text { Endoscopic extirpation of lesion of sigmoid colon } \\
\text { using rigid sigmoidoscope other specified }\end{array}$ \\
\hline & H269 & $\begin{array}{l}\text { Endoscopic extirpation of lesion of sigmoid colon } \\
\text { using rigid sigmoidoscope unspecified }\end{array}$ \\
\hline & H401 & Trans-sphincteric excision of mucosa of rectum \\
\hline & $\mathrm{H} 402$ & Trans-sphincteric excision of lesion of rectum \\
\hline & $\mathrm{H} 408$ & $\begin{array}{l}\text { Operations on rectum through anal sphincter other } \\
\text { specified }\end{array}$ \\
\hline & H409 & $\begin{array}{l}\text { Operations on rectum through anal sphincter } \\
\text { unspecified }\end{array}$ \\
\hline & $\mathrm{H} 412$ & Peranal excision of lesion of rectum \\
\hline \multirow{11}{*}{$\begin{array}{l}\text { Palliative } \\
\text { procedures }\end{array}$} & H13 & Bypass of colon \\
\hline & G74 & Creation of artificial opening into ileum \\
\hline & H141 & Tube caecostomy \\
\hline & H151 & Loop colostomy \\
\hline & H152 & End colostomy \\
\hline & $\mathrm{H} 214$ & $\begin{array}{l}\text { Fibreoptic endoscopic insertion of expanding metal } \\
\text { stent into colon }\end{array}$ \\
\hline & $\mathrm{H} 243$ & $\begin{array}{l}\text { Endoscopic insertion of tubal prosthesis into lower } \\
\text { bowel using fibreoptic sigmoidoscope }\end{array}$ \\
\hline & $\mathrm{H} 244$ & $\begin{array}{l}\text { Endoscopic insertion of expanding metal stent into } \\
\text { lower bowel using fibreoptic sigmoidoscope }\end{array}$ \\
\hline & $\mathrm{H} 273$ & $\begin{array}{l}\text { Endoscopic insertion of tubal prosthesis into sigmoid } \\
\text { colon using rigid sigmoidoscope }\end{array}$ \\
\hline & $\mathrm{H} 274$ & $\begin{array}{l}\text { Endoscopic insertion of expanding metal stent into } \\
\text { sigmoid colon using rigid sigmoidoscope }\end{array}$ \\
\hline & H314 & Image guided insertion of colorectal stent \\
\hline
\end{tabular}

